\title{
APPLICATION OF EFQM EXCELLENCE MODEL TO THE SABANCI UNIVERSITY IC
}

\author{
Asuman Akyüz - Technical Services Manager, asuman@sabanciuniv.edu \\ Sabancı University IC Tuzla, Istanbul - TURKEY
}

Total quality management (TQM), which was embraced in the last quarter of the 20th century, came to the forefront as an alternative to traditional management practices, and offers a modern, effective management approach characterized by continual improvement.TQM is defined as "A management style that holds customer expectations to be of the utmost importance and that achieves quality as defined by the customer in all aspects of operation with regard to products and services." (Toplam, 1994:12) This management style holds the expectations of internal and external users to be the basis for operation, and its goal is to continually empower employees and improve all processes through teamwork. Various models have been developed to implement total quality management. One of these is the "Excellence" model developed by the EFQM.

\section{EUROPEAN FOUNDATION FOR QUALITY MANAGEMENT (EFQM)}

This non-for-profit foundation has approximately 700 members in different disciplines from 50 countries. The foundation recommends the "Excellence" model to its members. Ever since 1992, the foundation has given a quality award to businesses that successfully implement this model. The foundation's goal is to empower members in being more productive in business and achieve better business results through the total quality management programs that are implemented. (EFQM, 2005)

\section{EFQM EXCELLENCE MODEL}

The EFQM's "Excellence" model (Figure 1) is a practical tool that assists organizations in developing their management systems by measuring whether or not they are improving in the area of excellence. It helps organizations to determine their strong points as well as areas with room for improvement, and encourages them to create solutions. The EFQM updates its model by gathering data from the best implementations of the model inside and outside of Europe. This ensures that the model is dynamic and reflects up-to-date management trends and practices.

An examination of the foundational concepts of the excellence model shows that it is made up of 9 primary criteria that consist of enablers and results. In the model, enablers and results are grouped and are equally weighted. The enabler criteria cover what an organization does. The results criteria show what that organization achieves. The results are achieved through enablers. The percentages specified for each criterion show the importance of that criterion in the overall model. The degree of the operational success of the business's total quality management is measured with each of the 9 primary criteria that the model contains. The model's superiority results from the relationships that have been created between the 9 criteria. In addition, the criteria are supported by various sub-criteria in order to provide a better understanding of each criterion. EFQM (2004). Arrows above and below the diagram emphasize the dynamic nature of model. They show that innovation and learning helps to improve enablers that in turn lead to improved results. 


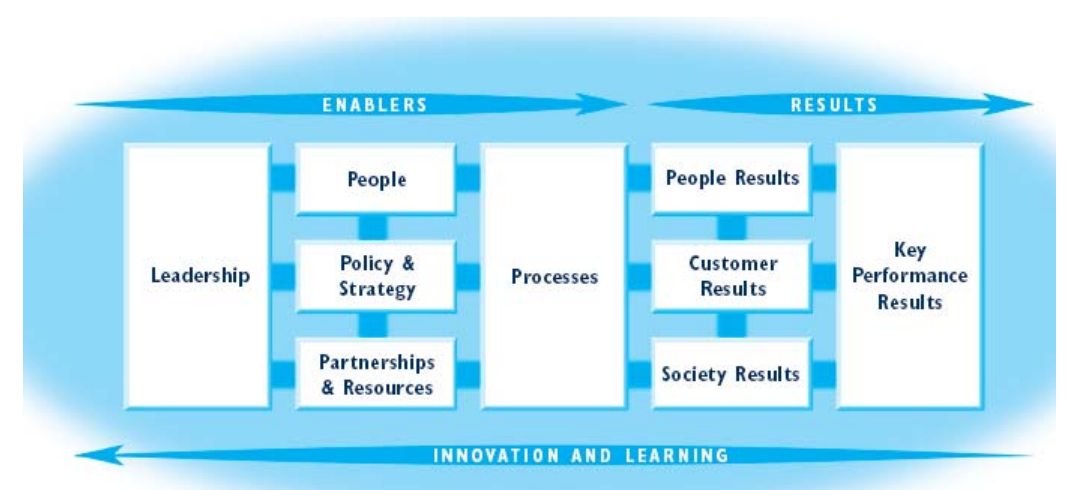

Figure 1.Source:EFQM, 2005

SABANCI UNIVERSITY (SU)

SU became a member of the EFQM in 1998. It is the first university in Turkey that has adapted all of its processes to the EFQM's Management's "Excellence" model. Naturally, this model is also implemented in the IC (IC), which is a unit of the university.

\section{CRITERIA OF THE EXCELLENCE MODEL AND THEIR CORRELATION WITH IMPLEMENTATION AT THE IC}

\section{Leadership}

Leadership is an important factor that affects the success of the implementation of TQM. It is also an important criterion in the excellence model. This criterion analyzes how the leader creates, supports and acts as a role model for a culture of excellence with his/her actions and behaviors.

\section{Policy and Strategy}

Policy and strategy is one of the most important factors, which enable the institutions to carry out its operations and be prepared for the future. This criterion evaluates operations based on the following questions: Whether the strategy and planning is developed based on appropriate and comprehensive information? How are strategies and plans announced, implemented? Whether they are regularly updated and improved? After the business goals and mission are defined, the sector is examined. A SWOT (Strengths, Weaknesses, Opportunities, Threats) analysis is carried out to identify the opportunities and threats in the sector, the organization's position in the sector, its strengths and weaknesses and development areas. The results of this analysis define the goals. Action plans are created to reach the goals. The results of all these efforts are evaluated according to the criteria of business results.

The IC identified its goal and mission when it was founded in 1998. The goal of the IC was defined as supporting the education, training and research programs of SU, meeting information and documentation needs of its academic and administrative staff and students in every form and format, and supporting the accumulation, usage and transfer of information on a national and international level. Its mission is to provide access to information and information sources rather than physical ownership. Strategy and policies are announced to employees at yearly meetings where goals are defined. Strategy and plans are revised and improved based on the results of environmental analysis, which is a part of 
SWOT analysis. Strategic planning carried out in 1998, set the 5-year collection goal as 100,000 bibliographic records for 1998-2003. Strategic planning goals were revised because of the economic problems experienced in Turkey in 2001 and reduced by $10 \%$ and became 90.000 . The bibliographic records were 92,150 at the end of 2003. The target in 5year plan was achieved.

\section{People}

Another important aspect of TQM is to enable active participation of employees in production, quality and improvement processes. This criterion analyzes how the human resources plan is developed and reviewed, and how employee participation and empowerment is achieved and requires evidence that these are implemented.

First of all, in order to create an open communication channel between management and employees, the IC created a web page for its own employees. This web page includes all kinds of information related to the employees; including processes, trainings, articles, projects, social activities, announcement, etc. In 2002, the IC initiated a new project-based method in order to encourage teamwork. The goal of this method is to: ensure employees to participate in management, improve motivation, increase creativity, develop team spirit and creative work environment, achieve improved communication, realize professional and individual improvement and inform employees about all operations carried out at the IC. Each employee would come with a project proposal by filling out the 'Project Proposal Form' on the web page. Proposals are evaluated by the management and if appropriate, a project team is formed. This team carries out its operations within the defined framework. The result of the project is presented to the management. If it is approved, the project is implemented.

\section{Partnerships and Resources}

In order for a business to survive and continue operation, all resources (financial resources, information resources, buildings, materials, equipment and technology) should be managed in an effective and efficiently way. With this criterion, the model analyzes how resources can be managed in an effective and efficiently way. Statistical information is used to evaluate whether or not resources are used effectively.

The Center has adopted the mission of "to provide access to information and information sources rather than physical ownership" ever since it was founded, and has been equipped with the technological infrastructure to access information in all forms and formats. In addition to this, the university gives each student a laptop computer at the enrollment stage. There are 8,000 Internet access points throughout the university and 480 access points in the IC. In addition, wireless access is in effect as of 2004. This powerful technological infrastructure and rapid change in the way information is recorded has driven the IC to develop its information holdings primarily in electronic format. As a result, the holdings, of which $3 \%$ were electronic in the year 2000 , have reached the point where $18 \%$ of books and $98 \%$ of periodicals were electronic in 2004 .

\section{Processes}

Information units of universities create value for users through their processes. For example, employees may be intelligent, capable, well trained and well motivated, and may 
be encouraged in various ways to increase their performance, but if their tasks have been poorly planned and organized, it will be impossible for them to do good work. Wellplanned processes are the starting point for an organization's success. Consequently, processes are the most important of the enablers and are given the most points. This criterion evaluates how processes are defined, reviewed and, when necessary, improved. It requires the definition of all the details of the processes that have the most effect on the work flow and are defined as key processes.

The IC has identified the following 6 primary processes: "Management of IC", "Developing and Organizing Collection", "Building Operation and Collection Maintenance", "Managing Services", "Utilizing Services" and "Archive of University History". These 6 processes include 10 instruction letters, 29 procedures and 125 documents. The instruction letters and processes are updated 2 times a year following an evaluation carried out with those persons in charge of the procedures. The instruction letters and procedures that are included in the process of managing services have been given in Table 1. Activities that result from all processes are measured and evaluated with statistics.

\section{Table 1. A540 - Managing Services}

Instruction: Managing IC Services IIC-A540-01

Procedures: Membership PIC-A540-0101, Loan PIC-A540-0102, Marketing of Information Services PICA540-0103, Reserve Collection PIC-A540-0104, Document Supply PIC-A540-0105, ILL PIC-A540-0106, IC Weekend and Night Shift PIC-A540-0107

Form and documents: Serials Selective Dissemination of Information Questionnaire FIC-A54001-10, General Service Evaluation Questionnaire FIC-A54001-12, Selective Dissemination of Information New Publications Form FIC-A54001-13, Loan Statistics Form - General Collection / User Type FIC-A54001-22, Marketing of Information Services Statistics Form - Reference - General FIC-A54001-25, Marketing of Information Services Statistics Form - Orientation FIC-A54001-27, Document Supply Statistics Form FICA54001-35, ILL Statistics Form FIC-A54001-36

\section{Customer Results}

The sixth criterion of the model evaluates to what degree customer needs and expectations are met. (EFQM, 2004)

SU is a university that is customer oriented and that considers customer satisfaction to be important. For example, orientation programs for new students are planned and prepared one month before the university opens. These programs are carried out by the rector, deans and some unit directors. The fact that the IC is one of these departments shows that the SU considers information and the IC to be important. Orientation programs for new students are initiated by the director, and continued through out the year. New faculty members undergo a different procedure. The first week that a faculty member begins work, the director sends a 'welcome' message and invites to drink a cup of coffee at the IC. Those who do not answer the first message within a week are reminded with a message saying, 'your coffee is getting cold'. The IC's facilities and services are described in this one-onone meeting with them. This first meeting with customers ensures that communication lines are opened between customers and the IC. This line of communication ensures that all services and facilities are used in a more effective and efficient way and increases customer 
satisfaction. In addition, customer satisfaction is measured and evaluated with statistics, face-to-face meetings and surveys regarding the services and facilities, both during orientation and during the times that customers make use of the IC.

Another activity is "SU Student and Staff Opinion Surveys", which was carried out by a company for the university in 2001. This survey showed that the operations are one of the strong points of the university. In addition, a survey carried out by the IC following orientation sessions in 2002 determined that customer satisfaction was over $90 \%$. The IC Director offered orientation sessions over 'A Cup of Coffee' to faculty in 2004. For instance, all of the faculty from the Grad. School of Man., including the dean, attended this orientation, and $90 \%$ of them that attended this program began to utilize the alerting services offered at the orientation sessions. In 2005, a survey will be used to evaluate the satisfaction of users that attend the orientation and take advantage of this service. An evaluation of the usage statistics for 2003 and 2004 indicates that the IC's services were used in an effective and efficient way. User feedback revealed that customer satisfaction was high. As can be seen in Table 2, an analysis of the usage statistics for 2004 shows that $93 \%$ of faculty requested information from the IC and that $98,5 \%$ of all users checked out resources from the IC. The $7 \%$ group that did not request information resources from the IC and the 1,5\% group that did not utilize check out services were chosen as the target group. Strategies are being developed to encourage these users to utilize the services.

Table 2.

\begin{tabular}{|c|c|c|c|c|c|c|}
\hline & & $\begin{array}{l}\text { Number of those that used } \\
\text { the service }\end{array}$ & $\%$ & $\begin{array}{l}\text { Number of those that did } \\
\text { not use the service }\end{array}$ & $\%$ & Total \\
\hline \multirow[t]{2}{*}{$\begin{array}{l}\text { Check } \\
\text { Services }\end{array}$} & $\begin{array}{l}\text { Undergraduate } \\
\text { Students }\end{array}$ & 1.986 & 98,5 & 31 & 1,5 & 2.017 \\
\hline & Faculty & 250 & 98,8 & 3 & 1,2 & 253 \\
\hline Requests & Faculty & 232 & 93 & 18 & 7 & 253 \\
\hline
\end{tabular}

\section{People Results}

This criterion attempts to measure how employees perceive the organization and the indicators that the organization uses to track employee satisfaction.

Because that the IC gives special importance to employee satisfaction, it measures and evaluates performance (Table 3), sends promising employees to education sessions for their professional and personal advancement, and rewards them by allowing to attend meetings inside and outside the country. In order to increase employee motivation, some other social activities are arranged, such as birthday parties, outdoor barbecues and New Years parties.

\section{Table 3. PERSONNEL PERFORMANCE EVALUATION - CATALOGUING}

\begin{tabular}{|l|l|l|l|}
\hline & $\begin{array}{l}\text { Number of } \\
\text { Resources. }\end{array}$ & Points & $\begin{array}{l}\text { TOTAL POINTS } \\
\text { (Number of Days } x \text { Number of Information Resources) }\end{array}$ \\
\hline Copy & & 1,80 \\
\hline Z39.50 & & \\
\hline Non-Marc Editing & & 2,00 \\
\hline Original & & 3,60 \\
\hline TOTAL & & \\
\hline
\end{tabular}




\section{Society Results}

This criterion gives importance to the organization's approach to quality of life, perception of the society regarding the protection of environmental and natural resources, and the organization's internal measurement scales.

In regard to this topic, the IC supports the founding of public libraries and provides support for their structural organization, administration and employee training. In order to help young graduates become acquainted with the real business world, an orientation program was instituted in 2002 and held every year since called 'After and Before (after education, before beginning working life). This program was offered to the top three students in the Library Schools from 3 universities. These 9 people were hosted by the IC for a one-week program that included presentation workflow process of the Center.

Key Performance Results (Results are called the Organization's Level of Excellency) Excellent organizations use comprehensive performance indicators for the key elements of their policies and strategies and as a result obtain successful results. Measuring output values according to various factors and efforts to increase the current values are essential for total quality management. Business results are the final criterion for directing efforts and determining priorities.

The final criterion in the model analyzes the organization's performance indicators and its financial performance indicators. In addition, in order to stay ahead of competitors, it is necessary to benchmark in the world. This requires comparisons to be made. In order for a business to excel, it must benchmark itself with competitors and with the best practices in the world, and it must implement better applications and practices. Comparisons are important in order to see what is obtained from specific improvements in all activities as a result of implementing total quality management. In keeping with this, the IC identifies its standing by comparing itself with other university libraries that it deems to be superior in the field. The IC prepares itself for the future by identifying its strong and weak points, opportunities and threats through comparison and SWOT analysis. (Table 4)

\section{Table 4. SABANCI UNIVERSITY IC - SWOT ANALYSIS}

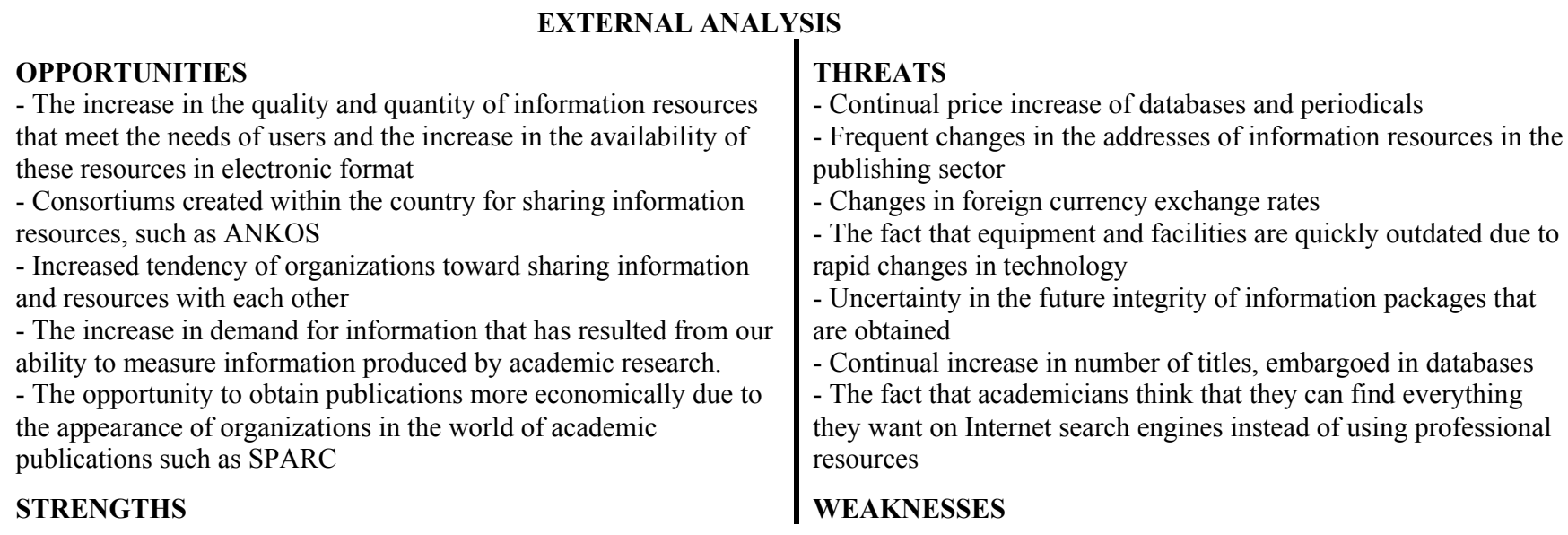


- The approach of the management to information and information services and fact that bureaucracy at the university has been reduced to a minimum

- Organizational Structure: Participation in decision making and management, teamwork

- The process and sub-processes are defined and written down

- A young, trainable and dynamic team that is loyal to the

organization / Sufficient human resources

- An impressive building; healthy and relaxed working conditions

- Technical infrastructure and equipment that meets all kinds of technological demands

- Software which features all necessary capabilities (Millenium)

- The university gives every student a laptop computer and that users are more easily able to access electronic resources

- 95\% of requests for document supply via ILL are met on the national and international level.

-Supplying Alerting services by profiles
- The lack of human resources necessary to market and promote the IC services and facilities to faculty and students of SU and external users, the difficulty in training workers of this type and the fact that the training takes a long time

- Employees do not have the desired language abilities

- The IC is a long distance away from eating and drinking facilities, which are frequently needed during work hours - Ineffective use of orientation programs

\section{ANALYSIS OF THE ORGANIZATION}

As a result of SWOT analysis, new strategic goals are established, action plans are prepared to strengthen weak points, preparation is made to meet threats, and plans are made accordingly. Table 5 shows the strategic goals for 2004-2007 that has been prepared for one process as a result of the IC's SWOT analysis.

\section{Table 5- IC DEPARTMENT GOALS, PERFORMANCE INDICATORS AND MEASUREMENTS OF PERFORMANCE 2004-2007}

\begin{tabular}{|c|c|c|c|c|c|}
\hline PROCESS & $\begin{array}{l}\text { DEPARTMENT } \\
\text { (IC) }\end{array}$ & $\begin{array}{l}\text { UNIVERSITY } \\
\text { GOAL }\end{array}$ & $\begin{array}{l}\text { DEPARTMENT } \\
\text { GOAL }\end{array}$ & $\begin{array}{l}\text { PERFORMANCE } \\
\text { INDICATOR }\end{array}$ & PERFORMANCE MEASUREMENT \\
\hline $\begin{array}{l}\text { A540-Providing } \\
\text { Services/A550- } \\
\text { Utilization of } \\
\text { Services }\end{array}$ & & $3 a, 5 e$ & $\begin{array}{l}\text { 1. Meeting document } \\
\text { and information needs } \\
\text { of users } \\
\text { 2. Supporting SU's, } \\
\text { education and research } \\
\text { programs } \\
\text { 3. Providing effective } \\
\text { services to SU Members }\end{array}$ & \begin{tabular}{|l|} 
Utilization Statistics / \\
Statistics on the \\
generation of material \\
to support class \\
lessons / Orientation \\
Program Results / \\
Survey for \\
Identifying Users' \\
Needs for Services
\end{tabular} & $\begin{array}{l}\text { Use of at least } 100,000 \text { full text articles from } \\
\text { the database per year } \\
\text { Check out of at least } 100,000 \text { volumes per year } \\
90 \% \text { rate for answering reference questions } \\
\text { At least } 90 \% \text { of students and } 40 \% \text { of faculty } \\
\text { members attending orientations } \\
\text { At least a } 40 \% \text { response ratio for the alerting } \\
\text { services }\end{array}$ \\
\hline
\end{tabular}

\section{CONCLUSIONS}

It is clearly evident that the model provides various theoretical and professional benefits as well as benefits for employees. These are as follows:

\section{From an Organizational Standpoint, this Model Will:}

Identify areas that are strong, weak and those with room for improvement; Allow the anticipation of opportunities and threats; Make it possible to see the current and future standing; Make it possible to carry out the mission, implement strategies and policies, and reach goals; Lay a foundation for forming and developing strategies and plans for improvement; Provide a tool for determining how much progress there is to be made in the area of quality management and determining where other university libraries are in that regard; Develop company culture; Achieve user satisfaction; Increase service quality; 
Speed up the decision making process; Increase productivity; Reduce number of procedures within each process; Reduce wasted resources and Make a contribution to society.

From the Perspective of the Employee, this Model Will:

Create a work environment in which the employee will be able to use their skills; Develop team spirit and teamwork; Increase awareness of TQM and create quality awareness; Increase motivation; Encourage clear and effective communication; Allow time for creativity by releasing the employee from routine tasks; Evaluate opportunities for performance and career development; Give the employee authority and responsibility; Offer satisfactory wages; Increase the standard of living; Most importantly and create a happy and peaceful work environment.

It is clear that the implementation of the excellence model will provide many benefits for information units of universities, which are considered part of the service sector. This model will make it possible for organizations to see their strong points and areas that need improvement, and will help organizations to identify how much progress needs to be made in the area of quality management, which is essential for forming strategies and plans for improvement. This model will also help organizations to identify how much progress other organizations have made in this area. In the end, information units of universities will only be able to succeed in the modern, competitive environment that is created by a changing world if they are managed with modern methods. As do many institutions, the IC believes in this modern approach to management and has the goal of excellence in products and services. The Center perceives the 'Excellence' model to be a robust instrument that will successfully assist the organization to achieve excellence. 